\title{
Virtual Reality Exposure Therapy for Anxiety and Specific Phobias
}

\author{
Thomas D. Parsons \\ University of North Texas, USA
}

\section{INTRODUCTION}

There is a growing body of research indicating the multiple ways that affective dysregulation (e.g., anxiety disorders, specific phobias, panic disorder, and posttraumatic stress disorder (PTSD)) may lead to significant impairments in normal life functioning. Anxiety and fear are concentrated emotional experiences that serve critical functions in organizing necessary survival responses (Fendt \& Fanselow, 1999). In properly functioning affective systems, the responses are adaptive. LeDoux (2012a) posits survival circuits that enable humans to adapt to feared stimuli by organizing brain functions. The fear induced arousal and activation of survival circuits allows for adaptive responses to take priority and other responses are inhibited. Further, attentional processing focuses on pertinent environmental stimuli and learning occurs (Scherer, 2000; LeDoux, 2012b). Hence, adaptive survival circuits are optimized to detect threatening stimuli and relay the information as environmental challenges and opportunities. The adaptive survival circuits use this information to adjust behavioral and psychophysiological responses for appropriate adaptation and resolution. Excessive fear responses, however, can be restrictive and may be a sign of dysregulated anxiety. When exposure to stress occurs early in development and is repeated in persons with a particular genetic disposition, a decreased threshold for developing anxiety may result (Heim \& Nemeroff, 1999). Further, over-excitation and deprivation can influence the affective system and may induce changes in the emotional circuitry of the brain that can contribute to stress-related psychopathology (Davidson, Jackson, \& Kalin, 2000).

A good deal of research has shown that exposure therapy is effective for reducing negative affective symptoms (Rothbaum \& Schwartz, 2002). In vivo exposure therapy has been found to have greater efficacy when compared to imaginal exposure, especially in the treatment of specific phobias (Emmelkamp, 2003). Exposure to emotional situations and prolonged rehearsal result in the regular activation of cerebral metabolism in brain areas associated with inhibition of maladaptive associative processes (Schwartz, 1998). Identical neural circuits have been found to be involved in affective regulation across affective disorders (De Raedt, 2006; Mineka, Watson, \& Clark, 1998). Systematic and controlled therapeutic exposure to phobic stimuli may enhance emotional regulation through adjustments of inhibitory processes on the amygdala by the medial prefrontal cortex during exposure and structural changes in the hippocampus after successful therapy (Hariri, Bookheimer, \& Mazziotta, 2000).

A novel tool for conducting exposure therapy is virtual reality exposure therapy (VRET), in which users are immersed within a computer-generated simulation or virtual environment (VE) that updates in a natural way to the user's psychophysiological arousal, head and/ or body motion (Parsons and Courtney, 2011, Parsons and Reinebold, 2012). Virtual environment applications that focus on treatment of affective (see Powers \& Emmelkamp, 2008; Parsons et al., 2008a; Opris et al., 2012) and cognitive disorders (see Rose et al., 2005; Parsons 2009a) as well as assessment of component cognitive processes are now being developed and tested: attention (Parsons, et al., 2007, 2011) spatial abilities (Beck et al., 2010; Goodrich-Hunsaker and Hopkins, 2010; Parsons, et al., 2013), memory (Moffat, 2009; Parsons \& Rizzo, 2008b; Parsons et al., 2013; Knight \& Titov, 2009), spatial memory (Parsons et al., 2013); and executive functions (Armstrong et al., 2013; Henry et al., 2012; Parsons et al., 2012, 2013, 2014). The increased ecological validity of virtual scenarios may aid differential diagnosis and treatment planning. Within a virtual world, it is possible to systematically present cognitive tasks targeting neuropsychological performance beyond what are currently available using traditional methods (Parsons, 2011, 2012).

DOI: 10.4018/978-1-4666-5888-2.ch636 
When users are immersed in a VE, they can be systematically exposed to specific affect inducing stimuli within a contextually relevant setting (Parsons et al., 2009a). VRET comports well with the emotionprocessing model, which holds that the fear network must be activated through confrontation with threatening stimuli and that new, incompatible information must be added into the emotional network (Foa and Kozak, 1986; Wilhelm et al., 2005). Although cyberpsychology researchers contend that VRET has been shown to be efficacious, a potential problem in interpreting and reconciling findings about the nature and extent of affective changes ensuing from VRET is that the vast majority of VRET studies have reported on small sample sizes and made use of inadequate null hypothesis significance testing. Until large-scale studies on the affective effects of VRET are published, statistical meta-analyses represent an interim remedy. Regrettably, the majority of VRET trials to date have made use of a range of different outcome measures (see Parsons and Rizzo, 2008a; Powers \& Emmelkamp, 2008; Opris et al., 2012). This chapter proffers potential resolutions to clinical heterogeneity of the outcome measures and inadequate reporting of results for VRET trials.

\section{BACKGROUND}

Empirical data from research assessing the efficacy of VRET on affective outcomes have been increasingly emerging over the last 10 years as VR systems have become less costly, more available and generally more usable. While much of the initial VRET research has been comprised of case studies, open clinical trials, and uncontrolled designs, a number of qualitative reviews (Botella et al., 2004; Glantz \& Rizzo, 2003; Hodges et al., 2001; Krign et al., 2004a; Pull, 2005) and more recently quantitative reviews (Parsons and Rizzo, 2008a; Powers \& Emmelkamp, 2008; Opris et al., 2012) of VRET have concluded that VRET has good potential as a treatment approach for anxiety and several specific phobias.

A potential problem in interpreting and reconciling findings about the nature and extent of affective changes ensuing from VRET is that a number of factors other than virtual reality exposure per se may be associated with such changes, including, for example, presence, immersion, anxiety and/or phobia duration, diagnostic groups, demographics (e.g. age, gender, and ethnicity). Furthermore, the vast majority of VRET studies have reported on small sample sizes and made use of inadequate null hypothesis significance testing. Until large-scale studies on the affective effects of VRET are published, statistical meta-analyses represent an interim remedy. Such analyses provide estimates of a population effect size across independent studies. They increase statistical power to detect true nonzero population effects by lowering the standard error, and consequently narrowing the confidence intervals associated with the population effect size estimate (Cohn \& Becker, 2003; Sackett et a., 1997).

In a recent meta-analysis comparing in vivo exposure, VRET and control conditions, Powers and Emmelkamp (2008) aimed to collect well-controlled studies that had either random or matched assignment of VRET for anxiety disorders. Although the literature search produced 95 studies that had evaluated anxiety and/or phobia before and after VRET, only 13 articles met the eligibility criteria for inclusion in the metaanalysis. While it is the case that a meta-analysis can be done with so few studies (i.e., 13 articles for Powers and Emmelkamp), the potential for inadequate ability to detect moderator variables may preclude one from so doing. Moderator variables are variables that impact the direction and/or strength of the relationship between an independent/predictor variable and a dependent/criterion variable (Baron and Kenny, 1986). Such variables are hypothesized to moderate or alter the magnitude of a relationship (e.g., gender; cybersickness; or immersability of the subject(s)). According to Hunter and Schmidt (1990; 1997), there are a number of problems with using a small number of studies to conduct a meta-analysis: 1) when sample size is viewed as the number of studies, the power to detect a given moderating variable relationship in the meta-analysis may be low; 2) with small numbers of studies, the moderators may be confounded with each other. For the Powers and Emmelkamp meta-analysis, this may be an even greater issue because they attempted to assess multiple hypotheses across groups (e.g. VRET, in vivo exposure, and control conditions) in a small number of studies $(\mathrm{N}=13)$ without adequate information related to potential moderators. Hence, the fact that the studies included in the meta-analysis did not provide adequate statistics severely limits the conclusions that can be drawn from the meta-analysis related to the differences between VRET and in vivo 
exposure. Parsons and Rizzo (2008a) limited their meta-analysis to magnitude of pre-/post-VRET-related changes in six domains and an overall effect size for affective functioning across studies (see Hall et al., 1994). They limited study selection to peer-reviewed journals that examined anxiety symptoms before and after VRET and were able to increase the available number of studies and limit confounds related to multiple groups. While the Parsons and Rizzo meta-analysis was more conservative (limited the analyses to one group) than that of Powers and Emmelkamp, it was less strict in its inclusion of case reports (Meyerbroker \& Emmelkamp, 2011).

Although the results for meta-analyses (Parsons \& Rizzo, 2008a; Powers \& Emmelkamp, 2008; Opris et al., 2012) revealed that VRET had statistically large effects on all affective domains, as well as all anxiety/ phobia groupings evaluated (Cohen, 1992, 1998), findings must be interpreted with caution given that many VRET studies do not include control groups, and many are not randomized clinical trials, limiting the confidence that affective enhancements were directly related to or caused by VRET. Even though VRET meta-analyses have attempted to identify possible moderators of affective improvements, this was not possible because necessary information was not reported or reported in insufficient detail. This lack of information related to affective improvements and presence, immersion, anxiety and/or phobia duration, demographics (e.g. age, gender, and ethnicity) may reflect a limited range of values given the selection criteria employed by most studies. Thus, the findings of these meta-analyses may not generalize to patients with anxiety disorders in general.

\section{FUTURE RESEARCH DIRECTIONS}

An important focus of this article is to proffer potential solutions to the problems of clinical heterogeneity of outcome measures and inadequate reporting of results for VRET trials. The goal is to offer a first step toward developing a standard way for VRET researchers to describe VRET trial findings in a manner that maximizes their critical appraisal and interpretation. As a result, the comparability of the VRET trials will be increased so that virtual reality researchers may better estimate the strength of the evidence in a qualitative analysis, calculate a pooled estimate of effect in a meta-analysis, and perform a moderator analysis. One example of an attempt to develop a standardized reporting of randomized clinical trials is the Consolidated Standards of Reporting Trials (CONSORT) statement. The CONSORT reporting standards would be very helpful for improving randomized clinical trials of VRET because it offers a standard way (including a checklist and flow diagram) to improve the quality of such reports. Further, it ensures that readers have the basic information necessary to evaluate the quality of a clinical trial (Mohler, Schultz, and Altman, 2001).

\section{Population Characteristics}

A crucial aspect of quality VRET studies is that authors adequately report the sampling strategy used so that readers may assess whether the sample reported upon is representative of the target population. This aspect of study design is critical because poor sampling will undermine the generalizability of the study and/or reduce the validity in situations where sampling bias is introduced. For study findings to be generalizable to the population as a whole, the sample must be representative of the population from which it is drawn. It is important for VRET researchers to address whether subjects in the different groups are similar in relevant attributes before and during the treatment (except for the treatment condition itself).

\section{Outcome Measures}

An important resolution to clinical heterogeneity of outcome measures in VRET research is the standardization of outcomes and the measures used to assess these outcomes. The selection of outcome measures for standardization need to be relevant to the patient's treatment and health status as well as psychometrically sound. Further, VRET measures need to be fully validated. A first step in this direction is establishing the theoretically derived relationship of a given variable of interest (e.g. anxiety as evidenced by the score on a scale) to other variables (Cronbach \& Meehl, 1955). This process refers to construct validation, which entails a psychometric assessment of the extent to which the correlation of a given measure (e.g. measure used to establish successful decrease in anxiety levels following VRET) to other measures (of either a similar or 
different domain) comports well with prior research findings (Drevillis, 2003).

\section{Reporting of Results}

Inadequate reporting of results in VRET studies may be resolved by establishing a standardized format for the presentation of data. Many journals now require that authors report means and standard deviations for all continuous study variables and the effect sizes for the primary study findings (International Committee of Medical Journal Editors,1997). The American Psychological Association emphasizes the importance of reporting effect sizes or similar statistics (e.g. "goodness-of-fit" indicators for structural equation modeling), in addition to the usual tests of statistical significance (American Psychological Association, 2001). Further, consistent with the APA Task Force on Statistical Inference, many journals require that researchers report confidence intervals for any effect sizes involving principal outcomes (Wilkinson, 1999). At a minimum, VRET studies should provide sufficient quantitative information to allow readers to evaluate the appropriateness of the analysis and to draw their own interpretations. The report should also include summary statistics (e.g., mean, standard error, and sample size) to show the data structure and to justify subsequent analyses. Researchers also need to ensure that the standard error calculation matches the study design (e.g. in a completely randomized design with subsamples, the correct standard errors for the levels of the main factor should be based on the experimental units, not the subsamples).

\section{Improving Presence and Immersion}

Although there has been a great deal of research into VRET over the last 15 years, the constructs of immersion and presence remain somewhat limited in their applicability. Although there have been attempts to increase utility of immersion and presence for applied challenges (see Chertoff et al., 2008), reviews of the literature reflect a lack of incorporation of this research into actual practice. This section discusses presence and immersion as essential components of experimental design.

Witmer and Singer (1998) address the complexity of presence and immersion by using surveys to segre- gate subjective levels of involvement and experience. Unfortunately, subjective measures tend to rely on post-test assessments of the user's feelings during the exposure to the VE, which is dependent on memory of the event (Witmer \& Singer, 1998). Self-report data are highly susceptible to influences outside the subject's own targeted attitudes (Slater \& Wilber, 1997). The item's wording, context, and format are all factors that may affect self-report responses. A limitation of questionnaire measures is that they can only be administered following a participant's immersion in a VE, but in order to assess participant experience during the actual immersion in a VE, researchers have sought more objective measure.

As a result, a quite different view seems to be emerging, in which presence is treated as something rooted in physiological and behavioral activity (Sanchez-Vives \& Slater, 2005; Parsons et al., 2012), as well as the relation between immersion and emotion (Banos et al., 2004; Meehan et al., 2005; Macedonio et al., 2007; Parsons \& Courtney, 2011). Presence and immersion researchers are increasingly incorporating psychophysiology into virtual reality environments. The use of psychophysiological measures in studies of persons immersed in high-fidelity VE scenarios offers the potential to develop current physiological computing approaches into affective computing scenarios. Such scenarios offer the potential for simulated environments to proffer cogent and calculated response approaches to real-time changes in user emotion, neurocognition, and motivation (Wu et al., 2013).

\section{CONCLUSION}

In conclusion, this manuscript attempted to bring attention to important factors related to studies using virtual reality exposure therapy. It is hoped that virtual reality clinicians and researchers will meet to establish a consensus and provide expert opinion on the available data, including appropriate research design and summary statistics. Further, such a panel could provide a better idea of which patients might be at increased risk of developing adverse affective sequelae and specify the baseline and follow-up monitoring that would be appropriate. This author does not believe such a statement will provide the final word on the subject. Indeed he looks forward to all future publications on the issue, 
which will undoubtedly enhance our knowledge and provide even better clinical guidance.

\section{REFERENCES}

American Psychological Association. (2001). Publication manual of the American Psychological Association (5th ed.). Washington, DC: Author.

Armstrong, C., Reger, G., Edwards, J., Rizzo, A., Courtney, C., \& Parsons, T. D. (2013). Validity of the Virtual Reality Stroop Task (VRST) in Active Duty Military. Journal of Clinical and Experimental Neuropsychology, 35, 113-123. doi:10.1080/13803395.2 012.740002 PMID:23157431

Banos, R. M., Botella, C., Alcaniz, M., Liano, V., Guerrero, B., \& Rey, B. (2004). Immersion and emotion: their impact on the sense of presence. Cyberpsychology \& Behavior, 7, 734-741. doi:10.1089/cpb.2004.7.734 PMID: 15687809

Baron, R. M., \& Kenny, D. A. (1986). The moderatormediator variable distinction in social psychological research: Conceptual, strategic and statistical considerations. Journal of Personality and Social Psychology, 51, 1173-1182. doi:10.1037/0022-3514.51.6.1173 PMID:3806354

Beck, L., Wolter, M., Mungard, N. F., Vohn, R., Staedtgen, M., Kuhlen, T., \& Sturm, W. (2010). Evaluation of spatial processing in virtual reality using functional magnetic resonance imaging (FMRI). Cyberpsychology, Behavior, and Social Networking, 13, 211-215. doi:10.1089/cyber.2008.0343 PMID:20528281

Blumenthal, T. D., Cuthbert, B. N., Filion, D. L., Hackley, S., Lipp, O. V., \& van Boxtel, A. (2005). Committee report: Guidelines for human startle eyeblink electromyographic studies. Psychophysiology, 42, 1-15. doi:10.1111/j.1469-8986.2005.00271.x PMID:15720576

Botella, C., Quero, S., Banos, R. M., Perpina, C., Garcia Palacios, A., \& Riva, G. (2004). Virtual reality and psychotherapy. Studies in Health Technology and Informatics, 99, 37-54. PMID:15295145
Chertoff, D. B., Schatz, S., McDaniel, R., \& Bowers, C. A. (2008). Improving presence theory through experiential design. Presence (Cambridge, Mass.), 17, 405-413. doi:10.1162/pres.17.4.405

Cohen, J. (1988). Statistical power analysis for the behavioral sciences (2nd ed.). Hillsdale, NJ: Lawrence Erlbaum Associates.

Cohen, J. (1992). A power primer. Psychological Bulletin, 112, 155-159. doi:10.1037/0033-2909.112.1.155 PMID:19565683

Cohn, L. D., \& Becker, B. J. (2003). How metaanalysis increases statistical power. Psychological Methods, 8, 243-253.doi:10.1037/1082-989X.8.3.243 PMID:14596489

Courtney, C., Dawson, M., Rizzo, A., Arizmendi, B., \& Parsons, T. D. (2013). Predicting Navigation Performance with Psychophysiological Responses to Threat In a Virtual Environment. Lecture Notes in Computer Science, 8021, 129-138. doi:10.1007/9783-642-39405-8_16

Courtney, C., Dawson, M., Schell, A., \& Parsons, T. D. (2009). Affective Virtual Reality Exposure: Psychophysiological Support for Increased Elicitation of Negative Emotions in High and Low Fear Subjects. Lecture Notes in Artificial Intelligence, 5638, 459-468.

Courtney, C. G., Dawson, M.E., Schell, A. M., Iyer, A., $\&$ Parsons, T.D. (2010). Better than the real thing: Eliciting fear with moving and static computer-generated stimuli. International Journal of Psychophysiology, 78, 107-114. doi:10.1016/j.ijpsycho.2010.06.028 PMID:20600370

Cronbach, L. J., \& Meehl, P. E. (1955). Construct validity in psychological tests. Psychological Bulletin, 52,281-302. doi:10.1037/h0040957 PMID:13245896

Davidson, R. J., Jackson, D. C., \& Kalin, N. H. (2000). Emotion, plasticity, context, and regulation: Perspectives from affective neuroscience. Psychological Bulletin, 126, 890-909. doi:10.1037/0033-2909.126.6.890 PMID:11107881 
De Raedt, R. (2006). Does neuroscience hold promise for the further development of behavior therapy? The case of emotional change after exposure in anxiety and depression. Scandinavian Journal of Psychology, 47, 225-236. doi:10.1111/j.1467-9450.2006.00511.x PMID:16696847

Devillis, R. F. (2003). Scale development: Theory and applications (2nd ed.). Thousand Oaks, CA: Sage.

Emmelkamp, P. M. G. (2003). Behavior therapy with adults. In M. Lambert (Ed.), Handbook of psychotherapy and behavior change (5th ed., pp. 393-446). New York: Wiley.

Fendt, M., \& Fanselow, M. S. (1999). The neuroanatomical and neurochemical basis of conditioned fear. Neuroscience and Biobehavioral Reviews, 23, 743-760. doi:10.1016/S0149-7634(99)00016-0 PMID:10392663

Foa, E. B., \& Kozak, M. J. (1986). Emotional processing of fear: Exposure to corrective information. Psychological Bulletin, 99, 20-35. doi:10.1037/00332909.99.1.20 PMID:2871574

Friedman, D., Brigni, A., Guger, C., Antley, A., Steed, A., \& Slater, M. (2006). Sharing and Analyzing Data from Presence Experiments. Presence (Cambridge, Mass.), 15(5), 599-610. doi:10.1162/pres.15.5.599

Glantz, K., \& Rizzo, A. (2003). Virtual reality for psychotherapy: Current reality and future possibilities. Psychotherapy (Chicago, Ill.), 40, 55-67. doi:10.1037/0033-3204.40.1-2.55

Goodrich-Hunsaker, N. J., \& Hopkins, R. O. (2010). Spatial memory deficits in a virtual radial arm maze in amnesic participants with hippocampal damage. Behavioral Neuroscience, 124,405-413. doi:10.1037/ a0019193 PMID:20528085

Hall, J. A., Rosenthal, R., Tickle-Degnen, L., \& Mosteller, F. (1994). Hypotheses and problems in research synthesis. In H. Cooper, \& L. V. Hedges (Eds.), The handbook of research synthesis. New York: Russell Sage Foundation.

Harbin, T. J., \& Berg, W. K. (1986). The Effects of Age and Attention upon Reflex Inhibition. Biological Psychiatry, 22,81-94. doi:10.1016/0301-0511(86)900220 PMID:3697460
Hariri, A. R., Bookheimer, S. Y., \& Mazziotta, J. C. (2000). Modulating emotional responses: Effects of a neocortical network on the limbic system. Neuroreport, 11,43-48. doi:10.1097/00001756-200001170-00009 PMID:10683827

Heim, C., \& Nemeroff, C. B. (1999). The impact of early adverse experiences on brain systems involved in the pathophysiology of anxiety and affective disorders. Biological Psychiatry, 46, 1509-1522. doi:10.1016/ S0006-3223(99)00224-3 PMID:10599479

Henry, M., Joyal, C. C., \& Nolin, P. (2012). Development and initial assessment of a new paradigm for assessing cognitive and motor inhibition: the bimodal virtual-reality Stroop. Journal of Neuroscience Methods, 210, 125-131. doi:10.1016/j.jneumeth.2012.07.025 PMID:22897988

Hodges, L., Anderson, P., Burdea, G., Hoffman, H., \& Rothbaum, B. (2001). Treating psychological and physical disorders with VR. IEEE Computer Graphics and Applications, 21, 25-33. doi:10.1109/38.963458

Hunter, J. E., \& Schmidt, F. L. (1990). Methods of meta-analysis: Correcting error and bias in research findings. Newbury Park, CA: Sage.

Hunter, J. E., \& Schmidt, F. L. (1997). Cumulative research knowledge and social policy formation: The critical role of meta-analysis. Psychology, Public Policy, and Law , 2, 324-347. doi:10.1037/1076-8971.2.2.324

International Committee of Medical Journal Editors. (1997). Uniform requirements for manuscripts submitted to biomedical journals. Journal of the American Medical Association, 277, 927-934. doi:10.1001/ jama.1997.03540350077040 PMID:9062335

Knight, R. G., \& Titov, N. (2009). Use of Virtual Reality Tasks to Assess Prospective Memory: Applicability and Evidence. Brain Impairment, 10, 3-13. doi:10.1375/brim.10.1.3

LeDoux, J. E. (2012a). Rethinking the emotional brain. Neuron, 73, 653-676. doi:10.1016/j.neuron.2012.02.004 PMID:22365542

LeDoux, J. E. (2012b). Evolution of human emotion A view through fear. Progress in Brain Research, 195, 431-442. doi:10.1016/B978-0-444-53860-4.00021-0 PMID:22230640 
Macedonio, M., Parsons, T. D., DiGiuseppe, D. A., Weiderhold, B., \& Rizzo, A. A. (2007). Immersiveness and Physiological Arousal within Panoramic Video-based Virtual Reality. Cyberpsychology \& Behavior, 10, 508-516. doi:10.1089/cpb.2007.9997 PMID: 17711358

Meehan, M., Razzaque, S., Insko, B., Whitton, M., \& Brooks, F. P. (2005). Review of four studies on the use of physiological reaction as a measure of presence in stressful virtual environments. Applied Psychophysiology and Biofeedback, 30, 239-258. doi:10.1007/ s10484-005-6381-3 PMID:16167189

Meyerbroker, K., \& Emmelkamp, P. (2011). Virtual reality therapy for anxiety disorders: The state of the art. In S. Brahnam (Ed.), Advanced Computational Intelligence Paradigms in Healthcare: Virtual Reality in Psychotherapy, Rehabilitation, and Assessment (pp. 47-62). Germany: Springer-Verlag. doi:10.1007/9783-642-17824-5_4

Mineka, S., Watson, D., \& Clark, L. A. (1998). Comorbidity of anxiety and unipolar mood disorders. Annual Review of Psychology, 49, 377-412. doi:10.1146/ annurev.psych.49.1.377 PMID:9496627

Moffat, S. D. (2009). Aging and spatial navigation: what do we know and where do we go? Neuropsychology Review, 19,478-489. doi:10.1007/s11065-009-9120-3 PMID:19936933

Moher, N., Schultz, K. F., \& Altman, D. (2001). The CONSORT statement: Revised recommendations for improving the quality of reports of parallelgroup randomized trials. Journal of the American Medical Association, 285, 1987-1991. doi:10.1001/ jama.285.15.1987 PMID:11308435

Opris, D., Pintea, S., García-Palacios, A., Botella, C., Szamosközi, S., \& David, D. (2012). Virtual reality exposure therapy in anxiety disorders: a quantitative meta-analysis. Depression and Anxiety, 29, 85-93. doi:10.1002/da.20910 PMID:22065564

Parsons, T. D., Bowerly, T., Buckwalter, J. G., \& Rizzo, A. A. (2007). A controlled clinical comparison of attention performance in children with ADHD in a virtual reality classroom compared to standard neuropsychological methods. Child Neuropsychology, 13, 363-381. doi:10.1080/13825580600943473 PMID:17564852
Parsons, T. D., \& Courtney, C. (2011). Neurocognitive and Psychophysiological Interfaces for Adaptive Virtual Environments. In C. Röcker, \& M. Ziefle (Eds.), Human Centered Design of E-Health Technologies (pp. 208-233). Hershey, PA: IGI Global.

Parsons, T.D., Courtney, C., Arizmendi, B., \& Dawson, M. (2011). Virtual Reality Stroop Task for Neurocognitive Assessment. Studies in Health Technology and Informatics, 143, 433-439. PMID:21335835

Parsons, T. D., Courtney, C., Cosand, L., Iyer, A., Rizzo, A. A., \& Oie, K. (2009b). Assessment of Psychophysiological Differences of West Point Cadets and Civilian Controls Immersed within a Virtual Environment. Lecture Notes in Artificial Intelligence, 5638, 514-523.

Parsons, T. D., Courtney, C., \& Dawson, M. (2014). Virtual Reality Stroop Task for Assessment of Supervisory Attentional Processing. Journal of Clinical and ExperimentalNeuropsychology. PMID:23961959

Parsons, T. D., Courtney, C., Dawson, M., Rizzo, A., \& Arizmendi, B. (2013). Visuospatial Processing and Learning Effects in Virtual Reality Based Mental Rotation and Navigational Tasks. Lecture Notes in Artificial Intelligence, 8019, 75-83.

Parsons, T. D., Courtney, C., Rizzo, A. A., Edwards, J., \& Reger, G. (2012). Virtual Reality Paced Serial Assessment Tests for Neuropsychological Assessment of a Military Cohort. Studies in Health Technology and Informatics, 173, 331-337. PMID:22357013

Parsons, T. D., Iyer, A., Cosand, L., Courtney, C., \& Rizzo, A. A. (2009c). Neurocognitive and Psychophysiological Analysis of Human Performance within Virtual Reality Environments. Studies in Health Technology and Informatics, 142, 247-252. PMID:19377160

Parsons, T. D., McPherson, S., \& Interrante, V. (2013). Enhancing Neurocognitive Assessment Using Immersive Virtual Reality. In Proceedings of the 17th IEEE Virtual Reality Conference: Workshop on Virtual and Augmented Assistive Technology (VAAT) (pp. 1-7).

Parsons, T. D., \& Reinebold, J. (2012). Adaptive Virtual Environments for Neuropsychological Assessment in Serious Games. IEEE Transactions on Consumer Electronics, 58, 197-204.doi:10.1109/TCE.2012.6227413 
Parsons, T. D., \& Rizzo, A. A. (2008a). Affective Outcomes of Virtual Reality Exposure Therapy for Anxiety and Specific Phobias: A Meta-Analysis. Journal of Behavior Therapy and Experimental Psychiatry,39,250-261.doi:10.1016/j.jbtep.2007.07.007 PMID:17720136

Parsons, T.D., \& Rizzo, A. A. (2008b). Initial Validation of a Virtual Environment for Assessment of Memory Functioning: Virtual Reality Cognitive Performance Assessment Test. Cyberpsychology \& Behavior, 11, 17-25. doi:10.1089/cpb.2007.9934 PMID:18275308

Parsons, T. D., Rizzo, A. A., Courtney, C., \& Dawson, M. (2012). Psychophysiology to Assess Impact of Varying Levels of Simulation Fidelity in a Threat Environment. Advances in Human-Computer Interaction, 5, 1-9. doi:10.1155/2012/831959

Parsons, T. D., Rizzo, A. A., Rogers, S. A., \& York, P. (2009a). Virtual Reality in Pediatric Rehabilitation: A Review. Developmental Neurorehabilitation, 12, 224-238. doi:10.1080/17518420902991719 PMID:19842822

Powers, M. B., \& Emmelkamp, P. M. G. (2008). Virtual reality exposure therapy for anxiety disorders: A metaanalysis. Journal of Anxiety Disorders, 22, 561-569. doi:10.1016/j.janxdis.2007.04.006 PMID:17544252

Pull, C. B. (2005). Current status of virtual reality exposure therapy in anxiety disorders: Editorial review. Current Opinion in Psychiatry, 18, 7-14. PMID:16639177

Rosenthal, R. (1979). The file drawer problem and tolerance for null results. Psychological Bulletin, 86, 638-641. doi:10.1037/0033-2909.86.3.638

Rothbaum, B. O., \& Schwartz, A. C. (2002). Exposure therapy for posttraumatic stress disorder. American Journal of Psychotherapy, 56, 59-75.PMID:11977784

Sackett, D. L., Straus, S. E., Richardson, W. S., Rosenberg, W., \& Haynes, R. B. (1997). Evidence-based medicine. How to practice and teach EBM (Vol. 7, pp. 169-182). New York: Churchill Livingstone.

Sanchez-Vives, M. V., \& Slater, M. (2005). From presence to consciousness through virtual reality. Nature Reviews. Neuroscience, 6, 332-339. doi:10.1038/ nrn1651 PMID:15803164
Scherer, K. (2000). Emotions as episodes of subsystem synchronization driven by nonlinear appraisal processes. In M. Lewis, \& I. Granic (Eds.), Emotion, development, and self-organization: Dynamic systems approaches to emotional development (pp. 70-99). New York: Cambridge University Press. doi:10.1017/ CBO9780511527883.005

Schwartz, J. M. (1998). Neuroanatomical aspects of cognitive-behavioural therapy response in obsessive-compulsive disorder. An evolving perspective on brain and behaviour. The British Journal of Psychiatry, 38-44. PMID:9534830

Slater, M. (2004). How colorful was your day? Why questionnaires cannot assess presence in virtual environments. Presence (Cambridge, Mass.), 13, 484-493. doi:10.1162/1054746041944849

Slater, M., \& Wilbur, S. (1997). A framework for immersive virtual environments (FIVE): speculations on the role of presence in virtual environments. Presence (Cambridge, Mass.), 6, 603-616.

Wilhelm, F. H., Pfaltz, M. C., Gross, J. J., Mauss, I. B., Kim, S. I., \& Wiederhold, B. K. (2005). Mechanisms of virtual reality exposure therapy: The role of the behavioral activation and behavioral inhibition systems. Applied Psychophysiology and Biofeedback, 30, 271-284. doi:10.1007/s10484-005-6383-1 PMID:16167191

Wilkinson, L.Task Force on Statistical Inference. (1999). Statistical methods in psychology journals. The American Psychologist, 54, 594-604. doi:10.1037/0003-066X.54.8.594

Witmer, B. G., \& Singer, M. J. (1998). Measuring Presence in virtual environments: A presence questionnaire. Presence (Cambridge, Mass.), 7, 225-240. doi:10.1162/105474698565686

Wu, D., Lance, B., \& Parsons, T. D. (2013). Collaborative Filtering for Brain-Computer Interaction Using Transfer Learning and Active Class Selection. PLoS ONE, 1-18. PMID:23437188 


\section{ADDITIONAL READING}

Kenny, P., Parsons, T. D., Rothbaum, B. O., Difede, J., Reger, G., \& Rizzo, A. A. (2009). Optimizing clinical training for the treatment of posttraumatic stress disorder using virtual patients. Studies in Health Technology and Informatics, 144, 264-268. PMID:19592778

Parsons, T. D. (2011). Neuropsychological Assessment using Virtual Environments: Enhanced Assessment Technology for Improved Ecological Validity. In S. Brahnam (Ed.), Advanced Computational Intelligence Paradigms in Healthcare: Virtual Reality in Psychotherapy, Rehabilitation, and Assessment (pp.271-289). Germany: Springer-Verlag. doi:10.1007/978-3-64217824-5_13

Parsons, T. D. (2011). Affect-sensitive Virtual Standardized Patient Interface System. In D. Surry, T. Stefurak, \& R. Gray (Eds.), Technology Integration in Higher Education: Social and Organizational Aspects (pp. 201-221). Hershey: IGI Global.

Parsons, T. D. (2012) Virtual Simulations and the Second Life Metaverse: Paradigm Shift in Neuropsychological Assessment. In V. Zagalo, T. Morgado. \& A. Boa-Ventura (Eds.), Virtual Worlds, Second Life and Metaverse Platforms: New Communication and Identity Paradigms (pp. 234- 250). Hershey: IGI Global.

Rizzo, A. A., Pair, J., Graap, K., Treskunov, A., \& Parsons, T. D. (2006). User-Centered Design Driven Development of a VR Therapy Application for Iraq War Combat-Related Post Traumatic Stress Disorder. Proceedings of the 2006 International Conference on Disability, Virtual Reality and Associated Technology, 113-122.

Rizzo, A. A., Parsons, T. D., Kenny, P., \& Buckwalter, J. G. (2012). Using Virtual Reality for Clinical Assessment and Intervention. In L. L'Abate, \& D. Palmer (Eds.), Handbook of Technology in Psychology, Psychiatry, and Neurology: Theory, Research, and Practice (pp. 277-318). Hauppauge, NY: Nova Science Publishers.
Rizzo, A.A., Parsons, T.D., \& Lange, B., Patrick Kenny, Buckwalter, J.G., Rothbaum, B.O., Difede, J., Frazier, J., Newman, B., Williams, J., \& Reger, G. (2011). Virtual Reality Goes to War: A Brief Review of the Future of Military Behavioral Healthcare. Journal of Clinical Psychology in Medical Settings, 18, 176-187. doi:10.1007/s10880-011-9247-2 PMID:21553133

\section{KEY TERMS AND DEFINITIONS}

Immersion: The state of consciousness where a person immersed in a virtual environment has diminished awareness of physical self-due to his or her being surrounded in engrossing virtual environment.

Post-traumatic Stress Disorder (PTSD): A clinical condition that may develop after a person is exposed to one or more traumatic events. PTSD represents a group of symptoms: recurring flashbacks, avoidance or numbing of memories, and hyperarousal.

Psychophysiology: The domain of psychology that is emphasizes the physiological bases psychological processes.

Survival Circuits: LeDoux (2012a) posits survival circuits that enable humans to adapt to feared stimuli by organizing brain functions.

Virtual Reality Exposure Therapy: A method of psychotherapy that uses virtual reality technology to treat patients with anxiety disorders and phobias.

Virtual Reality: An advanced form of human-computer interaction, in which users are immersed in an interactive and ecologically valid virtual environment. 